\title{
MLT gravity wave climatology in the South America equatorial region observed by airglow imager
}

\author{
A. F. Medeiros ${ }^{1}$, H. Takahashi ${ }^{2}$, R. A. Buriti ${ }^{1}$, J. Fechine ${ }^{2}$, C. M. Wrasse ${ }^{2}$, and D. Gobbi ${ }^{2}$ \\ ${ }^{1}$ Universidade Federal Campina Grande (UFCG), Av. Aprígio Veloso 882, Bodocongó, Campina Grande, Paraíba, \\ 58.109-170, Brazil \\ ${ }^{2}$ Instituto Nacional de Pesquisas Espaciais (INPE), Av dos Astronautas 1758, C. Postal: 515 São José dos Campos, São Paulo, \\ 12.201-970, Brazil
}

Received: 4 April 2006 - Revised: 10 November 2006 - Accepted: 27 November 2006 - Published: 8 March 2007

\begin{abstract}
An all-sky $\mathrm{CCD}$ imager for $\mathrm{OH}, \mathrm{O}_{2}$ and $\mathrm{OI}$ $(557.7 \mathrm{~nm})$ airglow emission measurements was operated at São João do Cariri (Cariri), Brazil $\left(7^{\circ} \mathrm{S}, 36^{\circ} \mathrm{W}\right)$, from October 2000 to December 2004. A large amount of image data, more than $3000 \mathrm{~h}$ of observation and around 1000 wave events, makes it possible to classify the gravity wave characteristics, which are statistically significant. The observed waves show a typically short horizontal wavelength (5$45 \mathrm{~km}$ ) and a short period (5-35 $\mathrm{min})$, and horizontal phase speeds of 1 to $80 \mathrm{~m} / \mathrm{s}$. In most cases band-type waves (horizontal wavelength between 10 and $60 \mathrm{~km}$ ) showed a clear preference for the horizontal propagation direction from the South American continent to the Atlantic Ocean. Ripples also have similar features but with different anisotropy. In this paper we focus our discussion on the wave characteristics of the bands and ripples and a comparison between them.
\end{abstract}

Keywords. Atmospheric composition and structure (Airglow and aurora; Instruments and techniques) - Space plasma physics (Wave-particle interactions)

\section{Introduction}

Since atmospheric internal gravity waves (hereafter gravity waves) have been recognized as an important atmospheric phenomenon (Hines, 1960), considerable observational and theoretical research has been carried out. These efforts have established the importance of such motions as a part of the driving force of the mean circulation and thermal structure in the mesosphere and Lower Thermosphere (MLT) region via wave energy and momentum transport (Fritts, 1993).

Airglow imaging provides a simple and useful method for investigating the horizontal characteristics of the gravity

Correspondence to: A. F. Medeiros

(afragoso@df.ufcg.edu.br) waves and their temporal evolution at MLT heights. Shortperiod gravity waves, with wavelengths from a few kilometers to a few hundreds of kilometers, have been studied by using sensitive cooled-CCD imagers measuring upper mesosphere airglow emissions (e.g. Taylor et al., 1995a; Nakamura et al., 2001; Swenson and Liu, 1998; Yamada et al., 2001; Ejiri et al., 2001, 2002; Smith et al., 2003; Shiokawa et al., 2003; Liu and Swenson, 2003; Wrasse et al., 2003; Medeiros et al., 2003, 2004a, b). Most of the airglow image measurements reported in the literature concern short-period $(<1 \mathrm{~h})$ wave structures and they fall into two distinct categories called "bands" and "ripples". Bands are extensive, long-lasting wave patterns which exhibit horizontal wavelengths of several tens of kilometers and horizontal phase velocities up to $100 \mathrm{~m} / \mathrm{s}$ (e.g. Clairemidi et al., 1985). These patterns have been attributed to freely propagating or ducted short-period gravity waves (Walterscheid et al., 1999; Isler et al., 1997; Taylor et al., 1987). On the other hand, ripples are short-lived $(<45 \mathrm{~min})$, small-scale wave patterns of restricted spatial extent (Peterson, 1979), and are thought to be generated in-situ by localized shear or convective-type instabilities in the background wind field (Taylor and Hapgood, 1990; Hecht et al., 1995; Hecht, 2004). The direction of the propagation of gravity waves is an important factor with respect to understanding their origin. Nakamura et al. (1999) analyzed 18 months of OH image data at Shigaraki $\left(35^{\circ} \mathrm{N}, 136^{\circ} \mathrm{E}\right)$, and found a seasonal variation of the wave characteristics. For the waves with a horizontal wavelength longer than $18 \mathrm{~km}$, the propagation direction was eastward in summer and westward in winter. Hecht et al. (2001) mentioned that most of the waves observed at Urbana $\left(40^{\circ} \mathrm{N}\right.$, $88^{\circ} \mathrm{W}$ ), during the summer solstice, originated from the south or southeast. Walterscheid et al. (1999) concluded, from 9 months of airglow image observations at Adelaide $\left(35^{\circ} \mathrm{S}, 138^{\circ} \mathrm{E}\right)$, that many waves were thermally ducted and for waves with horizontal wavelengths of a few tens of kilometers, the preferential propagation direction was poleward

Published by Copernicus GmbH on behalf of the European Geosciences Union. 


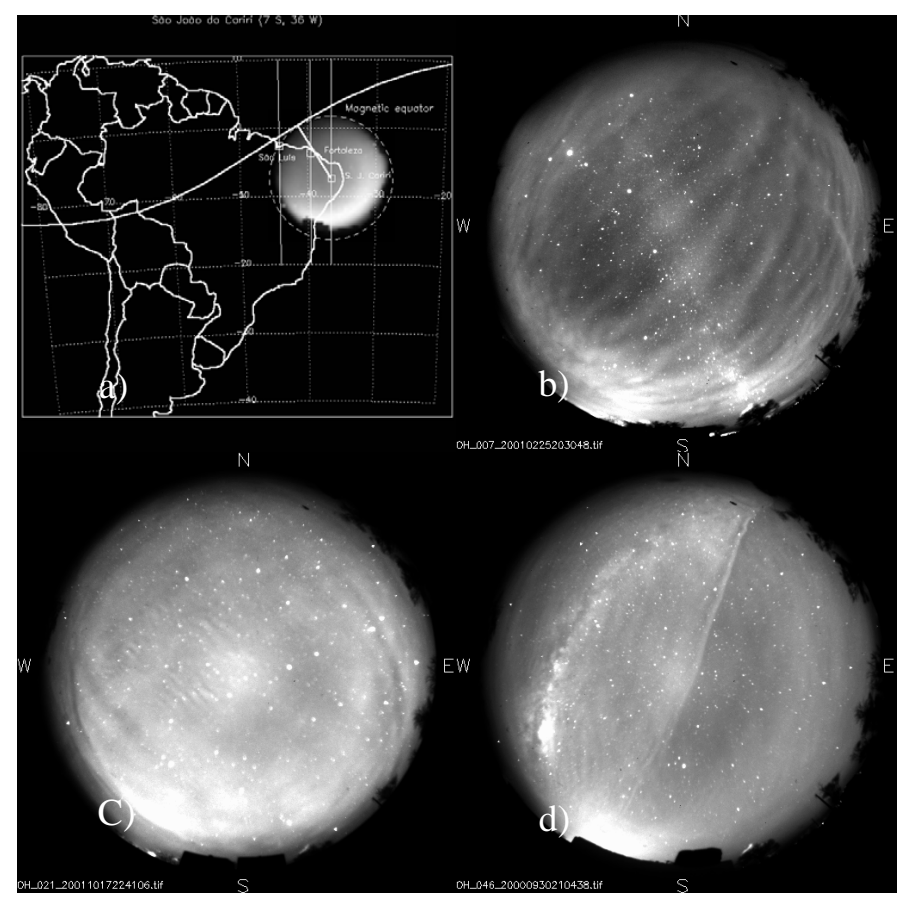

Fig. 1. Observation site map (a) and gravity waves imaged during observation period. Band (b), ripple (c) and bore (d).

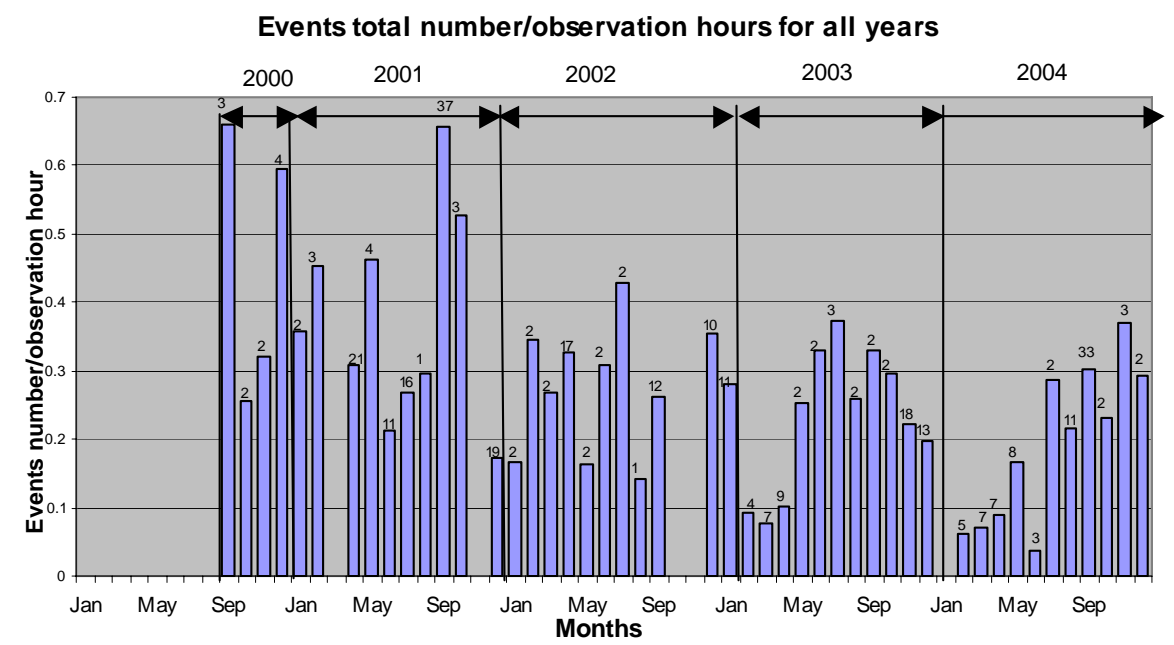

Fig. 2. Frequency of occurrence of waves (ripples and bands) at 1-month intervals. The number above each bar represents the total number of events for each bin.

in summer and equatorward in winter. Medeiros et al. (2003) reported that the propagation direction of the bands observed at Cachoeira Paulista $\left(22.7^{\circ} \mathrm{S}, 45.0^{\circ} \mathrm{W}\right)$ also showed a seasonal variation. In summer, the preferential propagation direction was towards the southeast. In winter, it was towards the northwest.

Taylor et al. (1997), for the first time, carried out airglow image observations at Alcantra $\left(2.3^{\circ} \mathrm{S}, 44.5^{\circ} \mathrm{W}\right)$ in South America. Later, Medeiros et al. (2003, 2004a) studied mesospheric gravity wave climatology from the airglow image data at Cachoeira Paulista $\left(23^{\circ} \mathrm{S}, 45^{\circ} \mathrm{W}\right)$ and São João do Cariri $\left(7^{\circ} \mathrm{S}, 36^{\circ} \mathrm{W}\right)$. In addition to these data, recently we obtained another data set during the COPEX (Conjugate Point Equatorial Experiment) Campaign at Boa Vista $\left(2.8^{\circ} \mathrm{S}\right.$, $60.7^{\circ} \mathrm{W}$ ) in 2002 . From the data for the three different locations, Medeiros et al. (2005) suggested that most of the gravity waves have their origin on the South American continent. 

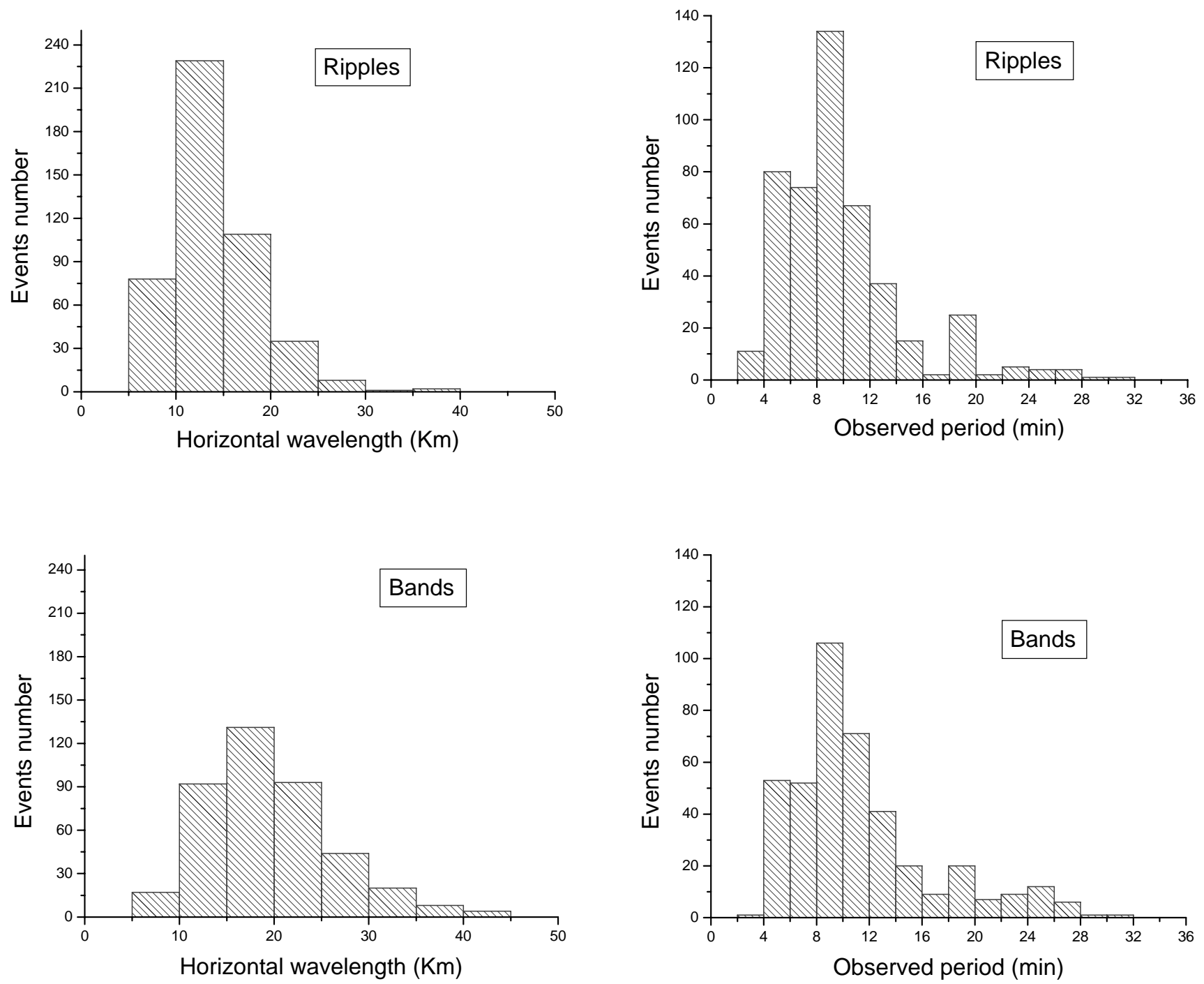

Fig. 3. Histogram of the horizontal wavelength for bands and ripples binned in 5-km intervals.

Previous studies by Medeiros et al. (2003, 2004a, b, 2005) were based on image data obtained over a fairly short period of time (a few months to one year). The Cariri airglow imager completed 4 years of observation in 2004, permitting us to investigate the wave characteristics with good statistical confidence. The main goal of this paper is, therefore, to construct a climatology of the short period gravity waves (ripples and bands) over Cariri, near the equator.

\section{Instrumentation and methodology}

Routine airglow observations have been carried out at Cariri using an all-sky imaging system. The CCD imager consists of a large area $\left(6.45 \mathrm{~cm}^{2}\right)$, high resolution, $1024 \times 1024$ backilluminated array with a pixel size of 14 bits. The high quan-

Fig. 4. Histogram of the observed period for bands and ripples binned in 2-min intervals.

tum efficiency ( $\sim 80 \%$ at visible wavelengths), low dark current $(0.5$ electrons/pixel/s), low readout noise ( 15 electrons $\mathrm{rms})$, and high linearity $(0.05 \%)$ of this device made it possible to achieve quantitative measurements of the airglow emissions. The camera uses a fast (f/4) all-sky telecentric lens system that enables us to obtain a high signal-to-noise ratio (20:1) image, with an integration time of typically $15 \mathrm{~s}$ for the near-infrared $\mathrm{OH}$ emission (715-930 nm pass-band) and $90 \mathrm{~s}$ for the OI, $\mathrm{O}_{2}$, and $\mathrm{OI}(630.0 \mathrm{~nm})$ emissions. The image was binned on-chip down to a $512 \times 512$ resolution to enhance the signal-to-noise ratio.

For the large-field information present in the all-sky data, accurate spatial calibration is essential. We can achieve this by using the stars in each image as known reference points in the sky. We determine the lens function by performing 

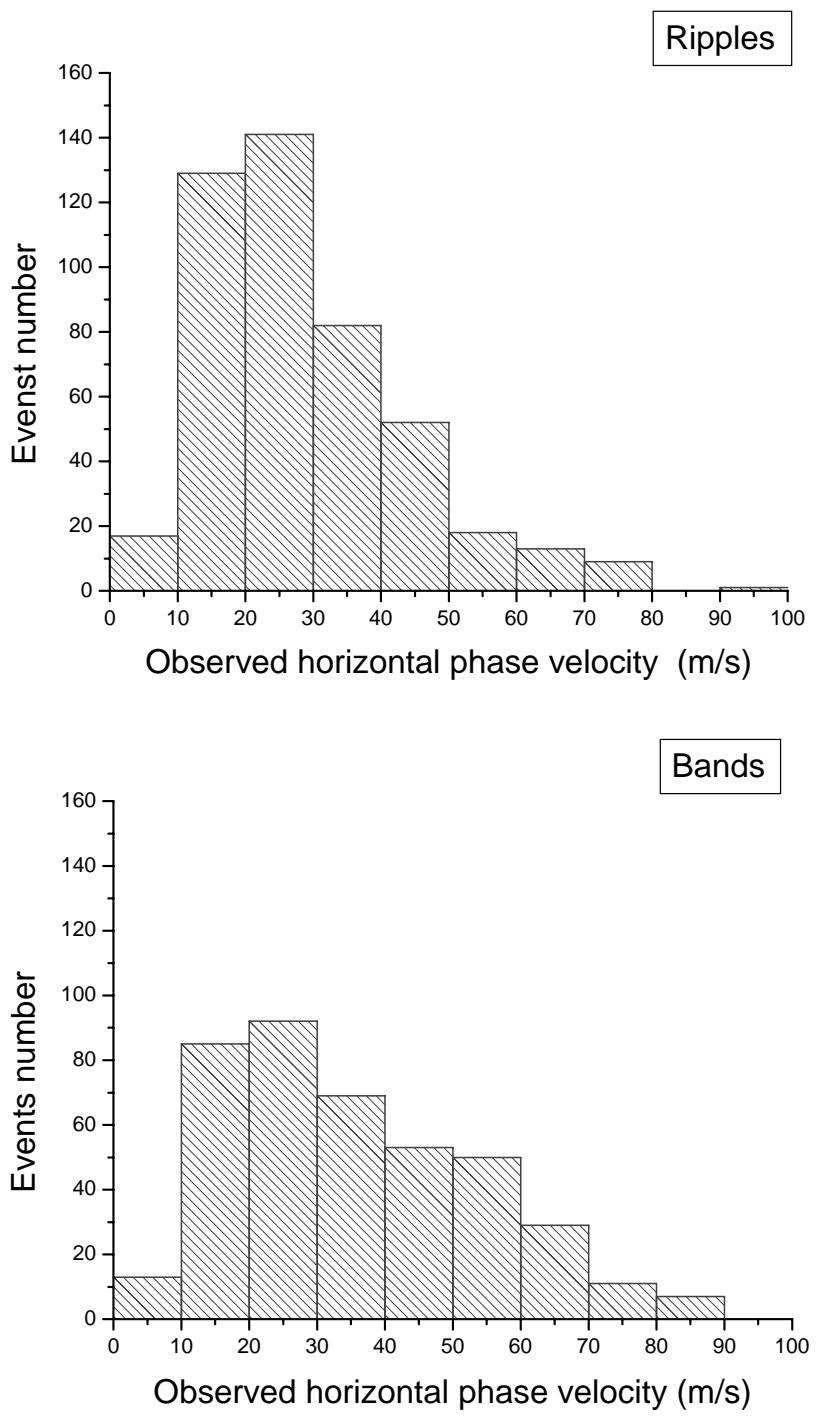

Fig. 5. Histogram of the observed horizontal phase velocity for bands and ripples binned in $10 \mathrm{~m} / \mathrm{s}$ intervals.

a least-squares fit using the measured position of the stars in the original image. After we have processed the all-sky images, it is now possible to determine the horizontal wave parameters directly with a standard 2-D FFT analysis. The advantage of this method is that all of the monochromatic features present in the image can be identified.

We can investigate gravity wave content in any part of the image by isolating the region of interest, taking the 2D FFT of the selected region and investigating peaks in the frequency spectrum. The determination of the period (and hence phase speed) of the waves present in these data involves taking the one-dimensional (1-D) temporal FFT of the complex 2-D spatial FFT. The peaks in the 1-D FFT correspond to the wave frequencies present in the data (Medeiros et al., 2003).
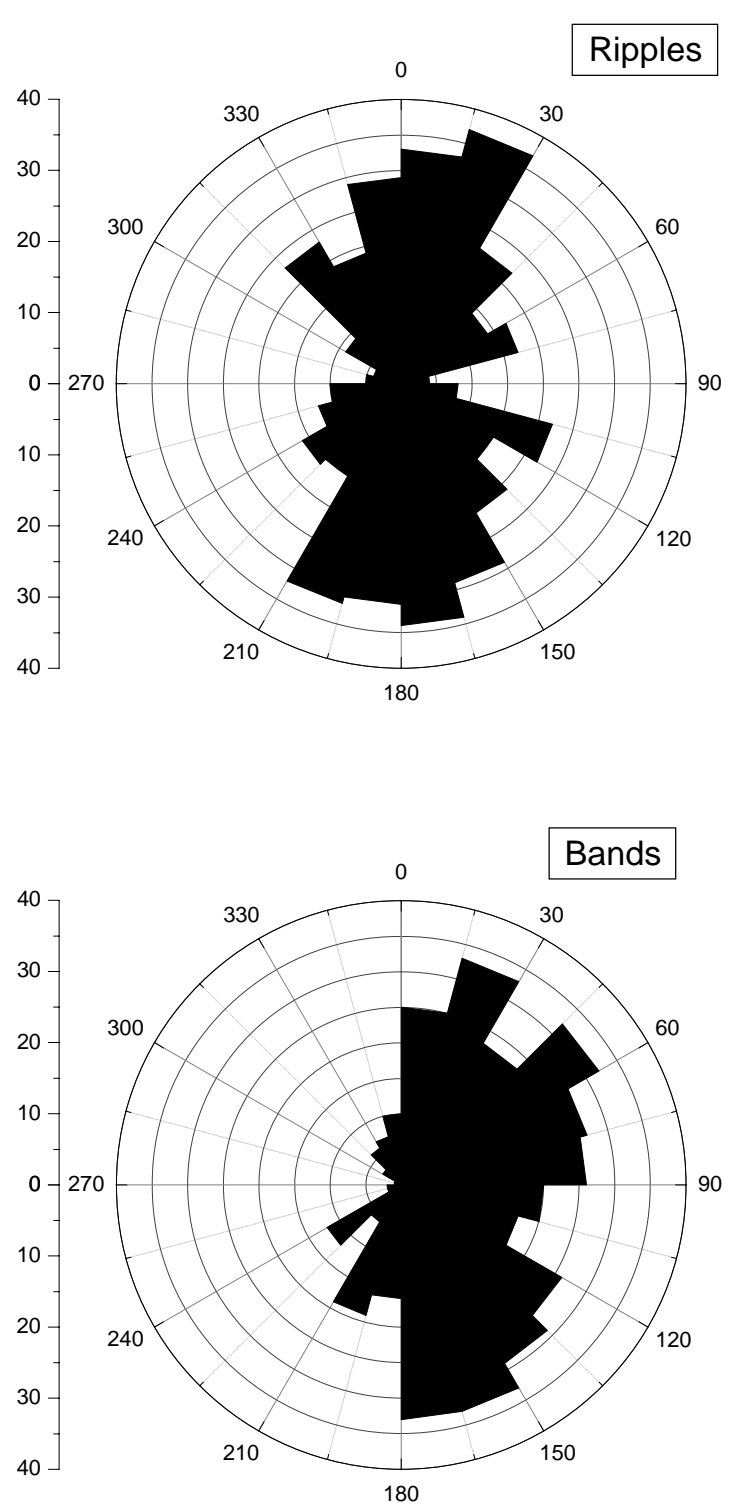

Fig. 6. Polar histogram of the propagation direction for bands and ripples binned in $15^{\circ}$ intervals.

\section{Results and discussion}

The airglow imaging system operated at Cariri $\left(7^{\circ} \mathrm{S}, 36^{\circ} \mathrm{W}\right)$ from October 2000 to December 2004. In Fig. 1 we show the observation site in the South American continent, together with examples of the mesospheric $\mathrm{OH}$ airglow images, band, ripples and a bore-like front. The field of view has an extension of about $800 \mathrm{~km}$ (at $90 \mathrm{~km}$ height). Despite the limitations imposed by meteorological conditions, approximately $3540 \mathrm{~h}$ of useful image data were recorded from about 500 nights, for which 1010 wave events were detected. From the total number of wave events, $48 \%$ were bands, while $52 \%$ 

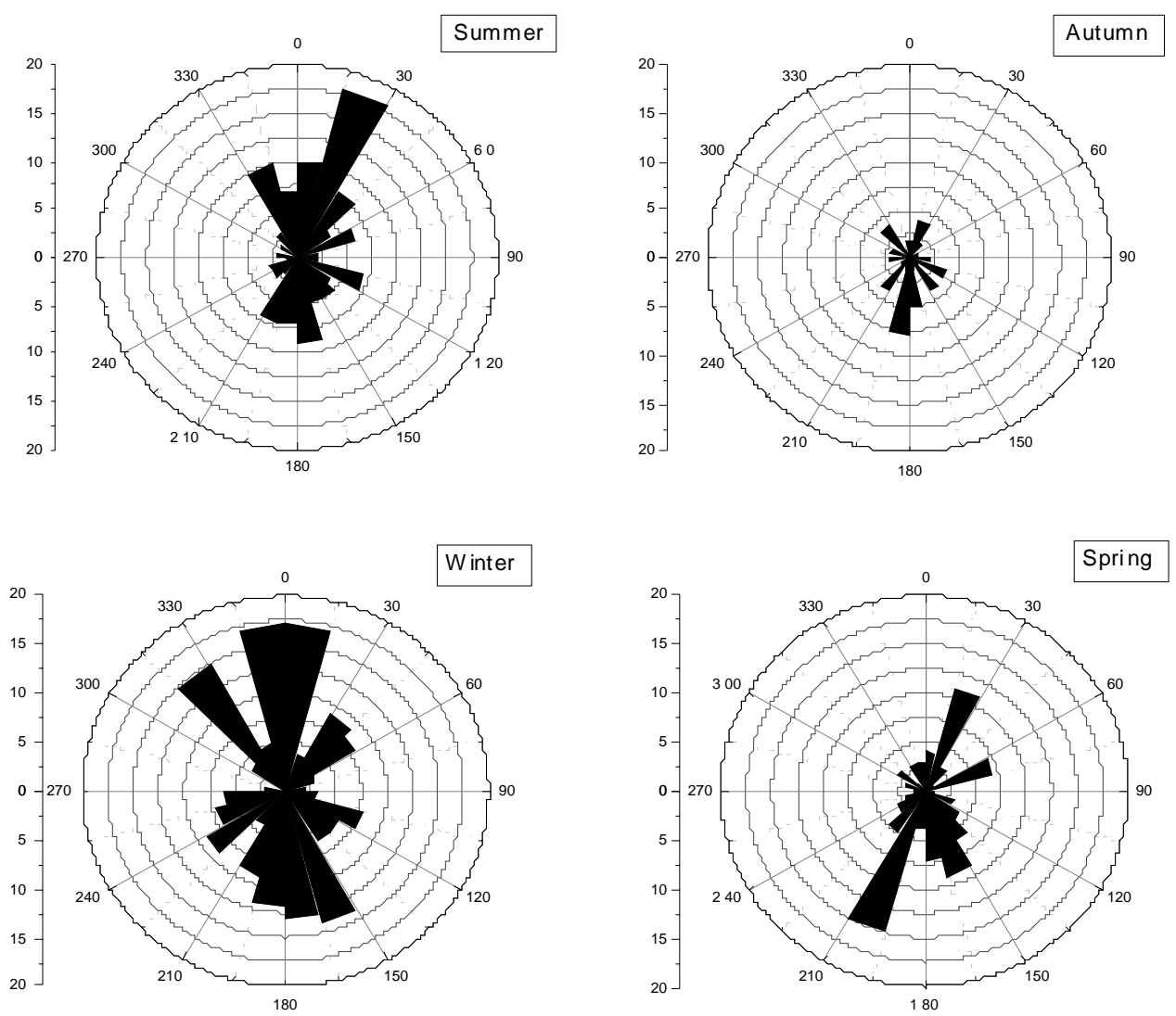

Fig. 7. Polar histograms of the propagation direction for ripples for each season.

were ripples. In the present work, the image analysis was focused only on the band and ripple waves, because bore-like fronts were included as bands. Two other studies on bore-like front classification have already been published (Medeiros et al., 2005, and Fechine et al., 2005). Frequency of occurrence of the wave events (bands and ripples) for each month during the period of observation is summarized in Fig. 2. The mean occurrence rate was 0.3 event/h. From the figure it can be noticed that the wave activity was high in 2001 and low in 2002. However, it is not clear whether there is an interannual variation or not. In 2003 and 2004, the wave activity was low during the February-April period.

Horizontal wavelengths are summarized in Fig. 3. The highest frequency of occurrence occurs in the range 10$15 \mathrm{~km}$ for the ripples and $15-20 \mathrm{~km}$ for bands. In the case of the ripples, $\sim 90 \%$ of the events have wavelengths within a range of 5-20 km, rather a narrow wavelength range. On the other hand, the bands are distributed in a broad range of horizontal wavelengths extending from 10 to $45 \mathrm{~km}$ and $88 \%$ of the bands have wavelengths longer than $10 \mathrm{~km}$. The average wavelengths are $20 \mathrm{~km}$ and $14 \mathrm{~km}$ for the bands and ripples, respectively. Taylor et al. (1997) reported an average wavelength of $24 \mathrm{~km}$ for bands and $11 \mathrm{~km}$ for ripples. Nakamura et al. (1999) observed spatial scales for these waves around
5-60 km. Ejiri et al. (2003) found that the gravity waves observed in OI images have longer wavelengths (around $27 \mathrm{~km}$ ) than those seen in $\mathrm{OH}$ images (around $21 \mathrm{~km}$ ). In our previous studies (Medeiros et al., 2003, 2004a), we reported that the averaged band wavelength was $23 \mathrm{~km}$, approximately twice that of the ripples $(13 \mathrm{~km})$. Our present results are in agreement with the previous study. The essentials of these results are summarized in Table 1.

The distributions of observed wave periods are shown in Fig. 4. The ripples exhibit a narrow range of distribution centered at 4-12 min (with $80 \%$ of the events occurring within this interval), with an average of $9.6 \mathrm{~min}$. The bands also showed a similar distribution but with a wide range of periods from 4 to $14 \mathrm{~min}$, with an average of $11.1 \mathrm{~min}$. Taylor et al. (1997) showed that the band-type waves have much longer periods than the ripples. Nakamura et al. (1999) reported that the observed waves (ripples and bands) had periods between 5 and $30 \mathrm{~min}$. Our previous work (Medeiros et al., 2004a) found that the ripples exhibit a remarkably sharp distribution centered on 6-10 min (with $70 \%$ of events occurring within this range) and an average wave period of $8.36 \mathrm{~min}$. In comparison, the bands exhibited an average wave period of $15.6 \mathrm{~min}$. 

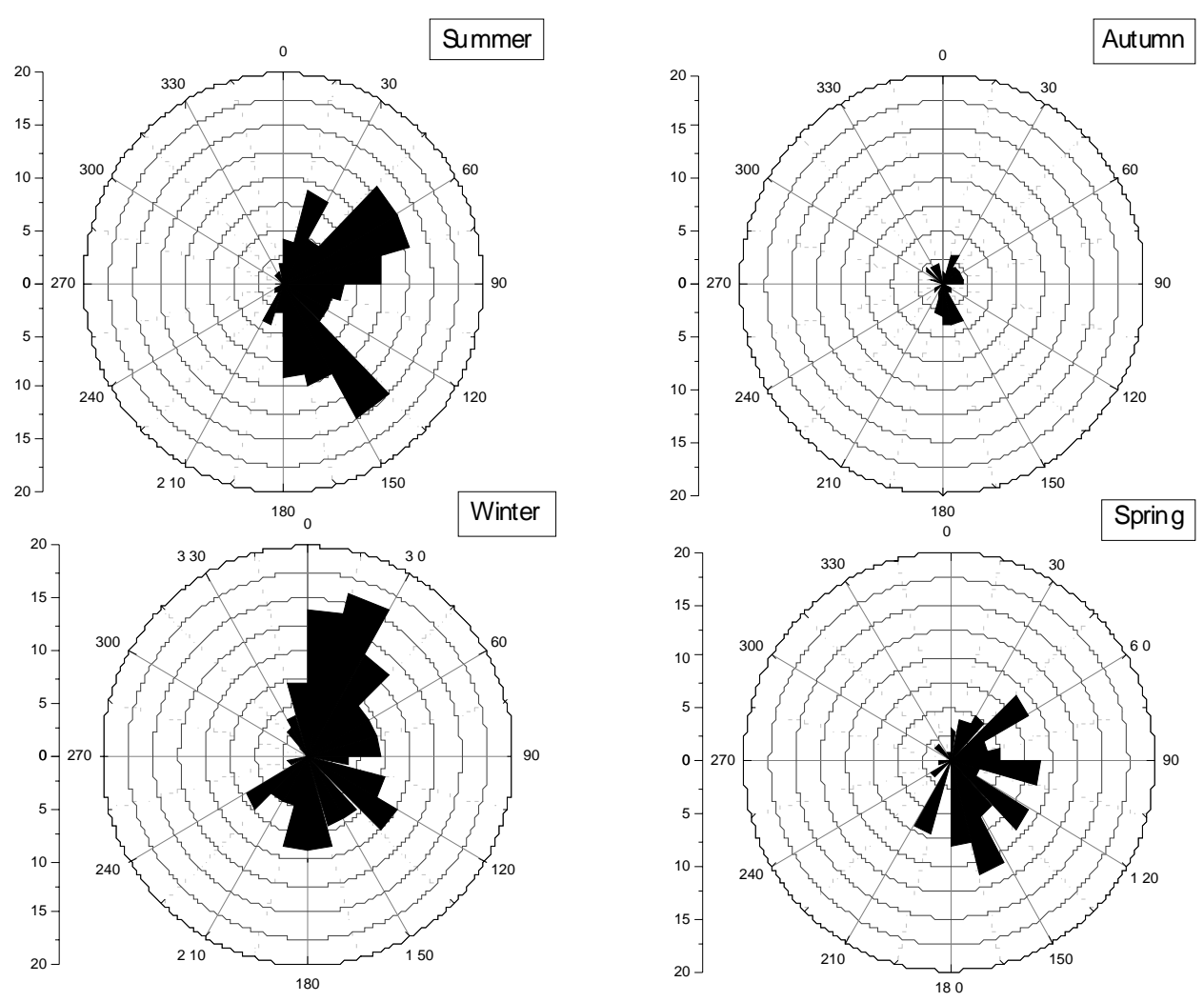

Fig. 8. Polar histograms of the propagation direction for bands for each season.

Table 1. Band and ripple characteristics from airglow image data ${ }^{a}$.

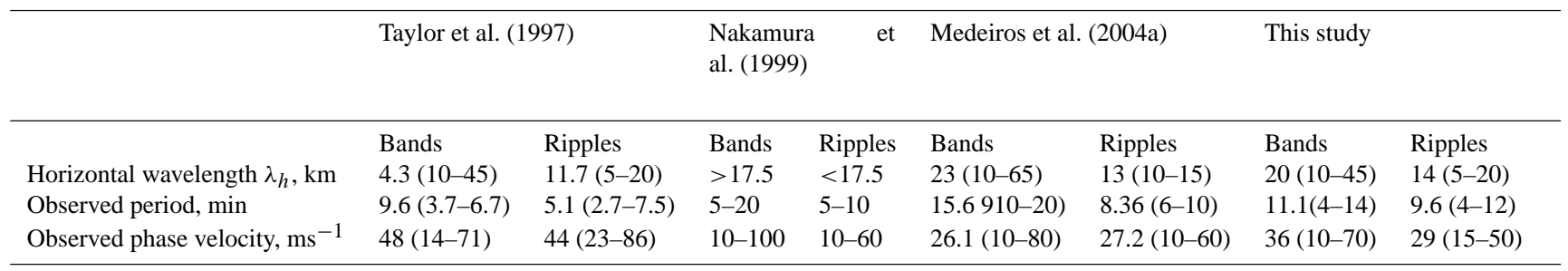

${ }^{a}$ : Average values are listed with the range given in parentheses, except where noted.

The observed phase velocities showed a difference between the ripples and bands. Figure 5 shows that the ripple phase velocities are within the range 10 to $50 \mathrm{~m} / \mathrm{s}$ with a peak at $20-30 \mathrm{~m} / \mathrm{s}$. On the other hand the bands go from 10 to $70 \mathrm{~m} / \mathrm{s}$, a rather wide range of velocity, higher than the ripples. The averaged phase velocity is $36 \mathrm{~m} / \mathrm{s}$ for the bands and $29 \mathrm{~m} / \mathrm{s}$ for the ripples. The observed speeds are higher than those observed in middle latitudes. Taylor et al. (1997) reported that the band velocities vary from 14 to $71 \mathrm{~m} / \mathrm{s}$ with an average of $48 \mathrm{~m} / \mathrm{s}$. The ripples exhibited a velocity distribution similar to the bands with an average of $44 \mathrm{~m} / \mathrm{s}$. Nakamura et al., (1999) found a similar phase velocity in summer and winter, varying from $0 \mathrm{~m} / \mathrm{s}$ to $100 \mathrm{~m} / \mathrm{s}$, with a peak at around $20-30 \mathrm{~m} / \mathrm{s}$. However, in spring and autumn the small phase velocities are not so frequent. Ejiri et al. (2003) observed horizontal phase speeds of $20-50 \mathrm{~m} / \mathrm{s}$ for the most frequently observed waves, and a few waves had velocities faster than $100 \mathrm{~m} / \mathrm{s}$. Medeiros et al. (2004a) reported band phase velocities from 10 to $80 \mathrm{~m} / \mathrm{s}$ with an average of $26.1 \mathrm{~m} / \mathrm{s}$. There is a clear tendency for many of the waves to exhibit phase speeds in the $10-40 \mathrm{~m} / \mathrm{s}$ range. The ripples exhibited a distribution in the range $10-60 \mathrm{~m} / \mathrm{s}$. The average phase speed was $27.2 \mathrm{~m} / \mathrm{s}$.

Propagation directions of the ripples and bands for all of the events during the period are shown in Fig. 6. The propagation directions are binned in $15^{\circ}$ intervals. The distribution 
of bands shows a clear preference of the propagation direction from the continent towards the Atlantic Ocean, eastward. There are very few cases where the bands propagated toward the west and southwest. The ripples also show a similar behaviour, but with different anisotropy. There are many cases with the propagation direction to northwest and southwest, not to be seen in the case of the bands. Zonal propagation (east-west) appears to be inhibited.

In order to see the seasonal dependency of the propagation direction, in Figs. 7 and 8, seasonally grouped polar histograms are shown for ripples and bands, respectively. During spring and summer, the ripples show propagation direction preferentially northeast and southwest. During winter propagation is in all directions except east, as can be seen from Fig. 6. In the case of the bands (Fig. 8), during summer the preferential propagation direction is towards the northeast and southeast. In winter the preferential propagation direction is towards the northeast, and in spring it is towards the southeast. It can be seen that the propagation directions of the ripples are spread over a wider range than the bands, especially in winter.

The anisotropy of the propagation direction of the bands and ripples may have two reasons, one is the effect of wave filtering by background winds in the lower atmosphere (stratosphere and mesosphere) and the other might be a changing gravity wave source region for the observer. The former is important at mid latitudes where the zonal wind system is strong (higher than $+/-40 \mathrm{~m} / \mathrm{s}$ ). In the equatorial region, on the other hand, the zonal winds are weak, less than $+/-20 \mathrm{~m} / \mathrm{s}$, except in summer $(-40 \mathrm{~m} / \mathrm{s})$ (Medeiros et al., 2004a, b). Therefore, the source region with respect to the observer is an important factor with respect to the propagation direction seen at Cariri. Medeiros et al. (2004a, b) reported that the gravity wave source should be in the South American continent (probably tropospheric convection activity). The present results, with much more image data, agree with this.

From the comparison of the wave parameters, wavelengths, periods, phase velocities and propagation directions between the ripples and bands, we could not find any clear difference, except their spatial extension and duration of occurrence. There are some differences in the phase velocity and propagation direction, but not much. Rather, both have common characteristics, as seen, which suggests to us that the ripple-type waves might be a part of the band-like waves, and spatially localized phenomenon. As mentioned before the ripples are believed to be generated in-situ by a localized wind shear or wave-wave interaction (e.g. Haurwitz and Fogle, 1969; Taylor and Hapgood, 1990). Recent studies on the ripples (Taylor et al.,1997, and Nakamura et al., 1999) suggests that they might not be primary propagating gravity waves but could be instability features generated in-situ. More recently, Hecht et al. (2005) confirmed this hypothesis experimentally by relating the occurrence of the ripples to regions of dynamical instability (wind shear). From our present study we are not able to discuss this point, but the similarity of the wave characteristics between the ripples and bands calls our attention and suggests further investigation of the difference in their physical processes.

\section{Conclusions}

The present work has presented results of gravity wave observations made by airglow imaging at Cariri $\left(7^{\circ} \mathrm{S}, 36^{\circ} \mathrm{W}\right)$ in the period October 2000 to December 2004. A total of the 300 nights, corresponding to $3540 \mathrm{~h}$ of observations, was analyzed. During the period, 1010 wave events were detected in $\mathrm{OH}, \mathrm{O}_{2}$ and OI5577 images. The mean rate of the events was 0.3 events $/ h$, with larger rates in the summer and winter months and smaller rates in autumn. Of a total of 1010 wave events $48 \%$ were classified as bands and $52 \%$ as ripples. No specific difference was found in the wave characteristics between the ripples and bands, except their spatial extension and duration and propagation direction. The distribution of bands shows a clear preference of the propagation direction from the continent towards the Atlantic Ocean. The ripples propagate preferentially to the north or south.

Acknowledgements. The Cariri imager was financed by PRONEX grant No. 76.97.1079.00. This work has also been supported by the Conselho Nacional de Desenvolvimento Científico e Tecnológico CNPQ.

Topical Editor U. P. Hoppe thanks two referees for their help in evaluating this paper.

\section{References}

Clairemidi, J., Herse M., and Moreels, G.: Bi-dimensional observation of waves near the mesopause at auroral latitudes, Planet. Space Sci., 33, 1013-1022, 1985.

Ejiri, M. K., Shiokawa K., Ogawa T., Kubota M., Nakamura T., and Tsuda T.: Dual-site imaging observations of small-scale wave structures through $\mathrm{OH}$ and OI nightglow emissions, Geophys. Res. Lett., 29(10), 1445, 2002.

Ejiri, M. K., Shiokawa, K., Ogawa, T. Nakamura, T., Maekawa, R., Tsuda, T., and Kubota, M.: Observations of small-scale gravity waves near the mesopause obtained from four all-sky CCD imagers and the MU radar, J. Geophys. Res., 106, 22 793-22 799, 2001.

Ejiri, M. K., Shiokawa, K., Ogawa, T., Igarashi, K., Nakamura, T., and Tsuda, T.: Statistical study of short-period gravity waves in $\mathrm{OH}$ and $\mathrm{OI}$ nightglow images at two separated sites, J. Geophys. Res., 108(D21), 4679-4790, 2003.

Fechine, J., Medeiros, A. F., Takahashi, H., Buriti, R. A., and Gobbi, D.: Mesospheric Bore Events In The Equatorial Middle Atmosphere, J. Atmos. Sol.-Terr. Phys., 67, 1774-1778, 2005.

Fritts, D. C. and Lu, W.: Spectral estimates of gravity wave energy and momentum fluxes. Part II: Parameterization of wave forcing and variability, J. Atmos. Sci., 50(22), 3695-3727, 1993.

Hecht, J. H., Howat, S. K. R., Waltersheid, R. L., and Isler; J. R.: Observations of spectra of intensity fluctuations of the 
OH Meinel nightglow during ALOHA-93, Geophy. Res. Lett., 22(20), 2873-2876, 1995.

Hecht, J. H.: Instability layers and airglow imaging, Rev. Geophys., 42, RG1001, 1-12, 2004.

Hecht, Liu, A. Z., Walterscheid, R. L., and Rudy, R. J.: Maui mesosphere and lower thermosphere (Maui MALT) observations of the evolution of Kelvin-Helmholtz billows formed near $86 \mathrm{~km}$ altitude, J. Geophys. Res., 110, 1029-1040, 2005.

Isler, J. R., Taylor, M. J., and Fritts, D. J.: Observational evidence of wave ducting and evanescence in the mesosphere, J. Geophys. Res., 102, 26301-26313, 1997.

Liu, A. Z. and Swenson, G. R.: A modeling study of $\mathrm{O} 2$ and $\mathrm{OH}$ airglow perturbations induced by atmospheric gravity waves, $\mathrm{J}$. Geophys. Res., 108(D4), 4151-4159, 2003.

Medeiros, A. F., Fechine, J., Buriti, R. A, Takahashi, H., Wrasse, C. M , and Gobbi, D.: Response Of Oh, O2 And Oi5577 Airglow Emissions To The Mesospheric Bore In The Equatorial Region Of Brazil, Adv. Space. Res., 35, 1971-1975, 2005.

Medeiros, A. F., Buriti, R. A., Machado, E. A., Taylor, M. J., Takahashi, H., Batista, P. P., and Gobbi, D.: Comparison of Gravity Wave Activity Observed by airglow imaging from two different latitudes in Brazil, J. Atmos. Sol.-Terr. Phy., 66/6-9, 647-655, 2004a.

Medeiros, A. F., Takahashi, H., Batista, P. P., Gobi, D., and Taylor, M. J.: Observation Of Atmospheric Gravity Waves Using Airglow All-Sky CCD Imager at Cachoeira Paulista $\left(23^{\circ} \mathrm{S}, 45^{\circ} \mathrm{W}\right)$, Geofísica Internacional, 43, 1, 29-39. 2004b.

Medeiros, A. F., Takahashi, H., Buriti, R. A., Pinheiro, K. M., and Gobi, D.: Atmospheric gravity wave propagation direction observed by airglow imaging in the South American Sector, J. Atmos. Sol.-Terr. Phys., 67, 1767-1773, 2005.

Medeiros, A. F., Taylor, M. J., Takahashi, H., Batista, P. P., and Gobi, D.: An Investigation of gravity wave activity in the lowlatitude upper mesosphere: propagation direction and wind filtering, J. Geophys. Res., 108(D14), 4411-4419, 2003.

Nakamura, T., Higashikawa, A., Tsuda, T., and Matsushita, Y.: Seasonal variations of gravity wave structures in $\mathrm{OH}$ airglow with a CCD imager at Shigaraki, Earth Planets Space, 51, 897-906, 1999.

Peterson, A. W. and Kieffaber, L. M.: Infrared photography of $\mathrm{OH}$ airglow structures, Nature, 242, 321-322, 1979.
Shiokawa, K., Ejiri, M. K., Ogawa, T., Yamada, Y., Fukunishi, H., Igarashi, K., and Nakamura, T.: A localized structure in $\mathrm{OH}$ airglow images near the mesopause region, J. Geophys. Res., 108(D2), 4048-4055, 2003.

Smith, S. M., Taylor, M. J., Swenson, G, R., She, C., Hocking, W., Baumgardner, J., and Mendillo, M.: A multidiagnostic investigation of the mesospheric bore phenomenom, J. Geophys. Res., 1083-1100, 108, 2003.

Swenson, G. R., Qian, J., and Plane, J. M. C., Espy, P. J., Taylor, M. J., and Turnbull, D. N. L. R. P.: Dynamical and chemical aspects of the mesospheric Na "wall" event on 9 October 1993 during Aiborne Lidar and Observations of Hawaiian Airglow (ALOHA) campaign, J. Geophys. Res., 103, 6361-6380, 1998.

Taylor, M. J. and Hapgood, M. A.: On the origin of ripple-type wave structure in the $\mathrm{OH}$ nightglow emission, Planet. Space Sci., 38(11), 975, 1421-1430, 1990.

Taylor, M. J. and Garcia, F. J.: A two-dimensional spectral analysis of short period gravity waves imaged in the $\mathrm{OI}(557.7 \mathrm{~nm})$ and near infra red $\mathrm{OH}$ nightglow emissions over Arecibo, Puerto Rico, Geophys. Res. Lett., 22, 2473-2276, 1995.

Taylor, M. J., Hapgood, M. A., and Rothwell, P.: Observations of gravity wave propagation in the OI $(557.7 \mathrm{~nm}), \mathrm{Na}(589.2 \mathrm{~nm})$ and the near infrared $\mathrm{OH}$ nightglow emissions, Planet. Space Sci, 35, 413-427, 1987.

Taylor, M. J., Pendleton Jr., W. R., Clark, S., Takahashi, H., Gobbi, D., and Goldberg, R. A.: Image measurements of short-period gravity waves at equatorial latitudes, J. Geophys. Res., 102(D22), 26 283-26 299, 1997.

Walterscheid, R. L., Hecht, J. H., Vicent, R. A., Reid, I. M., Woithe, J., and Hickey, M. P.: Analysis and interpretation of airglow and radar observations of quasi-monochromatic gravity waves in the upper mesosphere and lower thermosphere over Adelaide, Australia (35 S, 138 E), J. Atmos. Sol. Terr. Phys., 61, 461-468, 1999.

Wrasse, C. M., Nakamura, T., Tsuda, T., Takahashi, H. ,Gobbi, D., Medeiros, A. F., and Taylor, M. J.: Atmospheric Wind Effects On The Gravity Wave Propagation Observed At 22.7o S - Brazil, Adv. Space Res., 32, 5, 819-824, 2003. 